\title{
Investment scenarios and regional factors in the solar energy sector
}

\author{
Panagiotis Liargovas $^{1, *}$, Nikolaos Apostolopoulos ${ }^{2}$ \\ ${ }^{1}$ University of Peloponnese, Department of Economics, Greece \\ ${ }^{2}$ University of Plymouth, Plymouth Business School, UK
}

Received: 26 March 2016

Revised: 26 September 2016

Accepted: 5 October 2016

\begin{abstract}
This paper examines the effects of regional factors related to macroeconomic, environmental and energy data in relation to regional investment attractiveness to the Greek solar energy sector. Applying the Analytic Hierarchy Process method, the paper explores the significance of some criteria with reference to the regional investment attractiveness of solar energy enterprises. The AHP method is applied to approach investments in the solar energy sector, by incorporating regional factors in decision-making. Investment scenarios are created for the first time with the usage of multi-criteria methodology, and their scores are calculated based on regional factors Indeed, the results reveal that regions vary in terms of their investment attractiveness in the solar energy sector; hence, decision-makers and business managers should take regional factors into account. This study aims to contribute to the renewable energy expansion, as it is key to a sustainable economy and global challenges. As the last COP21 in Paris will lead to an overwhelming expansion of renewable energy, decision-makers should take into account not only national but also regional parameters.
\end{abstract}

Keywords: renewable; energy; investment; scenario; regional.

JEL Classification Codes: O13, 018, R11, M10

\section{Introduction}

All measurements and research show that Greece offers various investment opportunities in solar energy sector. Ernst and Young (2012), in their global solar index, placed Greece in $11^{\text {th }}$ position. Eurobserv'ER (2015), in its photovoltaic barometer for 2014, set Greece's photovoltaic power per inhabitant $\left(236.8 \mathrm{Wp}\right.$ /inhab) $4^{\text {th }}$ among European countries. The same report ranks Greece $6^{\text {th }}$ in regards electricity production from solar photovoltaic energy for 2013 and 2014. In the Global Market Outlook for Solar Power 2015-2019 (Solarpower, 2015) Greece

\footnotetext{
*Corresponding author. E-mail: liargova@uop.gr.

Citation: Liargovas, P. and Apostolopoulos, N. (2016) Investment scenarios and regional factors in the solar energy sector, Economics and Business Letters, 5(3), 95-104.
} 
is presented in a good position when it comes to solar power. Greece's leading position among European countries is highlighted in the IEA's (2014) report, as is the contribution of PV installations to Greece's electricity production.

The aforementioned studies and indexes explore national competitiveness and attractiveness, but the expansion of solar energy installations is not the same in all regions. Some regions manage to attract more investment and others less. In light of this, the present paper is devoted to examining and shedding light to the regional factors that contribute to new venture creation from a decision theory perspective. The purpose of this paper is to highlight the significant role of regional parameters by creating different scenarios based on regional investment attractiveness. The analysis is conducted by applying the Analytic Hierarchy Process (AHP), which entails complex issues related to integrated economic, social, political and environmental factors (Saaty and Vargas, 2001). The originality of this paper arises from the fact that it is the first time investment scenarios have been created using this methodological approach. It is also the first time that investment scenarios have been created in solar energy sector. We recognize, however, that defining regional attractiveness in solar energy plants goes beyond the comparison of different results among Greek regions. Given the nature of two recent studies, the novelty of this paper creates a clear border line. In the first study, Punia and Sindhu et al. (2016) prioritise the criteria of expanding renewable energy but explore India at the national level by applying group AHP and by using experts' opinions. In our study, we create investment scenarios based on regional parameters, with a focus on the sub-national level. Within the second study, Aragonés-Beltrán (2014) utilise both AHP and Analytic Network Priority (ANP) through the lens of project management by applying various criteria. With this said however, our research employs a different approach, comparing the alternatives between each with respect to each criterion and its actual measurements. Aragonés-Beltrán (2014) conducts comparisons between alternatives with respect to each criterion by using Saaty's rating scale from 0-9. As mentioned in the last chapter, the combination of the two aforementioned articles in terms of criteria selection could give the research in this field a significant boost forward. Notably, significant practical benefits are generated for policy-makers and business managers, as the identification of attractiveness is a navigator when it comes to the facilitation of investments.

This paper is structured as follows. After the introductory section, the second section encompasses a theoretical discussion related to regional competiveness and solar energy enterprises. The third section is devoted to the AHP methodology and its procedure. In the fourth section, the AHP method is applied in the case of 13 Greek regions. Policy implications are discussed within the section five. Finally, the last section includes some concluding remarks, research limitations and future perspectives.

\section{Theoretical discussion}

As far as regional economies are concerned, the OECD (2011) in its work on green growth mentions that rural regions are attractive for investments related to renewable energy due to land availability and natural resources. Regional areas can be strengthened economically by exploiting renewable energy technology (Allan, Mcgregor, and Swales, 2011). Every region can seek to exploit its renewable energy perspective and contribute to the nation's performance (Bull and Bilman, 2000). Regions with high levels of solar irradiation and technological knowledge can exploit those parameters and propel solar energy entrepreneurship.

Only through green business and new venture creation in the renewable energy sector can there be a transition to a green economy and sustainable regions. Innovation (Motohashi, 1998) and knowledge (Prahalad and Hamelzai, 1990) cumulatively affect an enterprise's economic sustainability and competitiveness. In the rapidly growing solar energy sector, innovation and 
knowledge play an essential role in achieving high efficiency. The role of an energy sector that is sustainable, competitive and secure is underlined as vital to the European regions (Commission of European Communities, 2008).

The AHP method has a wide range of applications. It has been employed in various economic fields, for instance in banking-sector evaluation in Turkey (Seçme, Bayrakdaroglu, \& Kahraman, 2009), in the supply chain for products (Wang, Huang and Dismukes, 2004), in business-source allocation (Saaty et al. 2003, Kearns, 2004) and in industry strategies for international markets (Chen and Wang, 2010). It has also been used in many cases concerning investment location, regional competitiveness and the renewable energy sector. $\mathrm{Wu}$ and $\mathrm{Wu}$ (1984) employed the AHP approach in plant location, thus underlining the benefits of using the AHP method in complicated situations. The work of Ke et al. (2011) was about wind-farm site selection in which economic and social criteria are set. Likewise, Aras et al. (2004) employed the AHP method to choose an appropriate area for a wind observation station. Wang and Feng (2002) applied the AHP method to rural areas in China. Nevima and Kiszova (2012) applied the AHP method to evaluate the regional macroeconomic data of regions in the Czech Republic. Jovanović, Filipović and Vukman (2016) employ the AHP to facilitate energy improvement in Serbia's manufacturing sector by setting five criteria and collecting AHP questionnaires from experts.

It has also been used in the case of achieving sustainable competitiveness for the textile industry in China (Xiao, 2012). Nagesha and Balashandra (2006) developed Saaty's method for use in India's small-scale industries. In addition, financial and economic barriers and behavioural and personal barriers are significant parameters in energy efficiency. Toosi et al. (2013) propose a decision model, based on AHP, oriented towards decision-makers who focus on energy policy. In this work, economic and technical criteria are set in order to choose an appropriate energy system. China's energy strategy and selection of main power resources to boost the economy are analyzed in He's and Guo's (2011) work by using the AHP method. The research finds that talent is the main parameter that affects competitiveness. Hämäläinen and Karjalainen's (1992) work is devoted to supporting Finland's decision-makers in relation to energy policies; this work also employs AHP, among other methods. Decision-making in the renewable energy sector presents a multidimensional standpoint due to social, environmental and economic factors that interact (Afgan and Carvalho, 2002). The method followed to make a decision should take into consideration the multidimensional nature of the problem and, depending on the desired approach, weigh economic, technical, social or environmental factors. Lee et al. (2008) employed the AHP method to define the competitiveness of Korea in hydrogen energy production. Their approach focused on comparing Korea with other countries by integrating the existence of the criterion of an $R \& D$ budget.

\section{AHP methodology}

Analytic Hierarchy Process moves through three main steps, plus another testing one. The first step is decomposition of the problem; we split a complex problem into parts that include goals, criteria and alternatives. The second step, after determining a hierarchy, is pairwise comparisons, on which the AHP method is based. The third step is a synthesis of priorities, which can be achieved with either a distributive or an ideal mode. Finally, a consistency test assesses the reliability of our judgements.

Assuming $n$ elements of a hierarchy $C_{1}, \ldots C_{n}$, the purpose is to estimate the relative weight of $C_{i}$ with respect to $C_{j}$. Then, $a_{i j}$ symbolizes the number that represents the comparison of $C_{i}$ with $C_{j}$. All the $a_{i j}$ form a square matrix $A=\left(a_{i j}\right)$ of order $n$. When the matrix holds that $a_{i j}=$ $1 / a_{j i}$, for $i \neq j$, and $a_{i i}=1$, then this matrix has a reciprocity characteristic.

If $A$ is a consistency matrix, weights $W_{i}$ and judgements $a_{i j}$ create a relation of the form: 


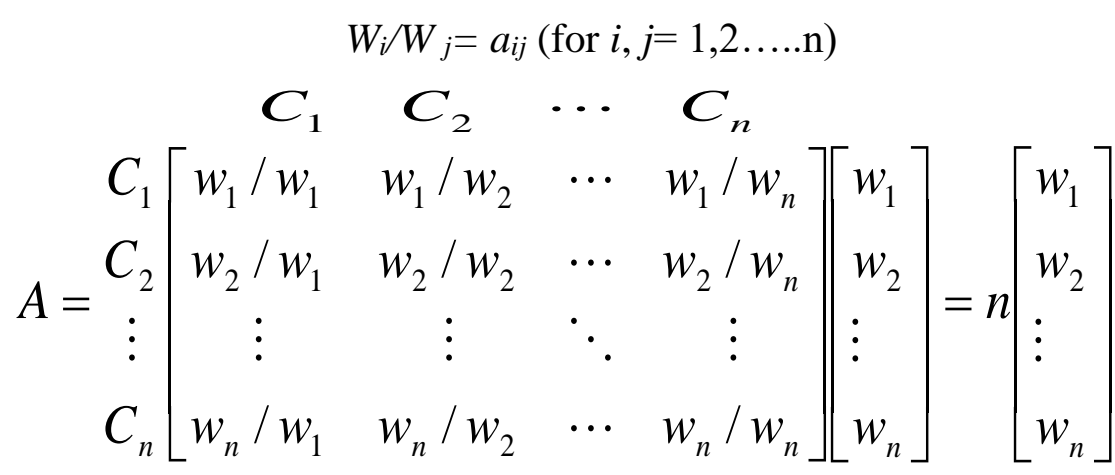

In order for the judgements to be consistent and hold the exact values of $\mathrm{w}_{\mathrm{i}} / \mathrm{w}_{\mathrm{j}}$, the vector $\mathrm{w}$ should satisfy: $A w=\lambda_{\max } w$ for $\lambda_{\max } \geq n$, where $\lambda_{\max }$ is the largest or principal eigenvalue.

When all the paired comparisons of elements are applied, the vector of priorities, $w=\left[w_{1}, w_{2}\right.$, $\left.\ldots, w_{n}\right]$, can be estimated through eigenvector calculation. The aforementioned process stops when the elements of the vector $w=\left(w_{1}, w_{2} \ldots, w_{n}\right)$ have no difference or only a small one between the power of $\mathrm{n}$ and that of $n+1$. After calculating the eigenvector, we must obtain the eigenvalue $\lambda_{\max }$ in order to estimate the consistency. According to Saaty and Vargas (2001), the largest eigenvalue $\lambda_{\max }$ will be $\lambda_{\max }=\sum_{j=\{1, . . n\}} a_{i j}\left(W_{j} / W_{i}\right)$.

$\lambda_{\max }$ is calculated by multiplying the priority vector by the summing result of each column of the matrix. $\lambda_{\max }$ should be $\lambda_{\max } \geq n$. If any value of $\lambda_{\max }$ is less than $\mathrm{n}$ it means that we have made an unacceptable estimation.

A measurement of inconsistency is calculated through the consistency index:

$$
C I=\frac{\lambda_{\max }-n}{n-1}
$$

To calculate the consistency ratio, we compare $C I$ with an appropriate number from an average random consistency index table, as presented by Saaty. As Saaty mentions, the table is produced from a large sample of reciprocal matrices.

If the Consistency Ratio=CI/RI is less than 0.10, then the matrix is consistent and the judgements are acceptable. In the opposite case, i.e. Consistency Ratio $>0.1$, it suggests that the judgements are not reliable. However, if Consistency Ratio is slightly above 0.1, the comparisons may sometimes be accepted. For Consistency Ratio above 0.9 the comparisons are completely unreliable.

Table 1. Average Random Consistency.

\begin{tabular}{c|cccccccccc}
\hline \hline \multicolumn{10}{c}{ Average Random Consistency Index $(R I)$} \\
\hline \hline$n$ & 1 & 2 & 3 & 4 & 5 & 6 & 7 & 8 & 9 & 10 \\
\hline$R I$ & 000 & 0.00 & 0.52 & 0.89 & 1.11 & 1.25 & 1.35 & 1.40 & 1.45 & 1.49 \\
\hline \hline
\end{tabular}

\section{AHP application}

A decomposition of the problem creates the goal, 10 criteria and 13 alternatives. The target is regional investment attractiveness. The alternatives are the 13 Greek regions, as they are defined in the European categorization of Eurostat (Fig. 1).

In order to accomplish the goal, 10 economic, energy and environmental criteria are incorporated. These criteria are defined based on Porter's diamond-model theory (Porter, 1990) about comparative advantage (Fig. 2) and by embodying the special characteristics of solar energy production (solar irradiation). Porter's model incorporates "factor conditions", 
"strategy and rivalry", "related and supporting industries" and "demand conditions". According to Porter, factor conditions are parameters that might affect production, such as capital, human resources or raw materials availability. Demand conditions can include international or national consumption. Related and supporting industries indicate the collaboration and synergies. Strategy and rivalry could be macro or micro parameters which might create a comparative advantage. Based on Porter's approach, this study is customised at the regional level, and in the case of comparative advantage of renewable energy.

Figure 1. Regional factors (criteria) and regions (alternatives) from applying AHP.

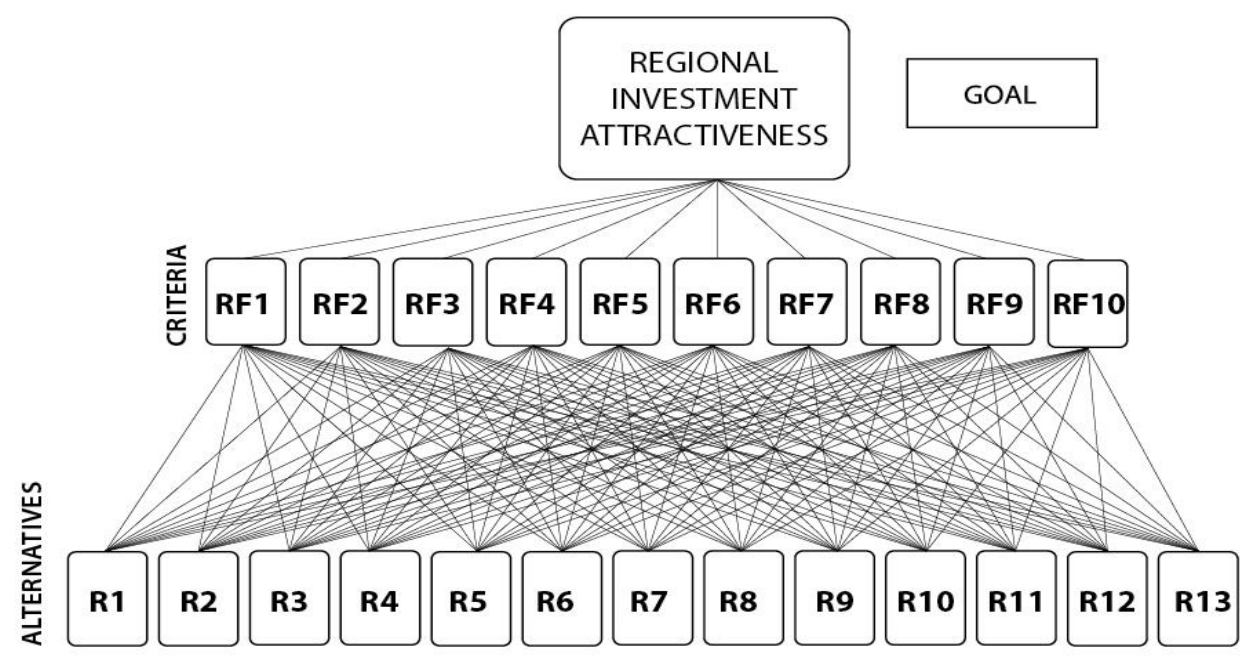

RF 1: Regional electricity consumption

RF2: Employment rate

RF3: Resource absorbance of EU Funds in digital governance and entrepreneurship

RF4: Resource absorbance of EU Funds in sustainable development and quality of life

RF5: Available land

RF6: GDP per capita

RF7: Gross, Fixed Capital Formation

RF8: Human resources in science and technology

RF9: Solar irradiation

RF 10: Photovoltaic energy installed

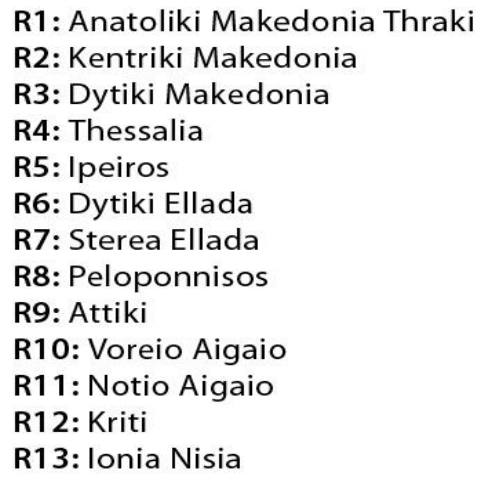


Figure 2. Porter's diamond model.

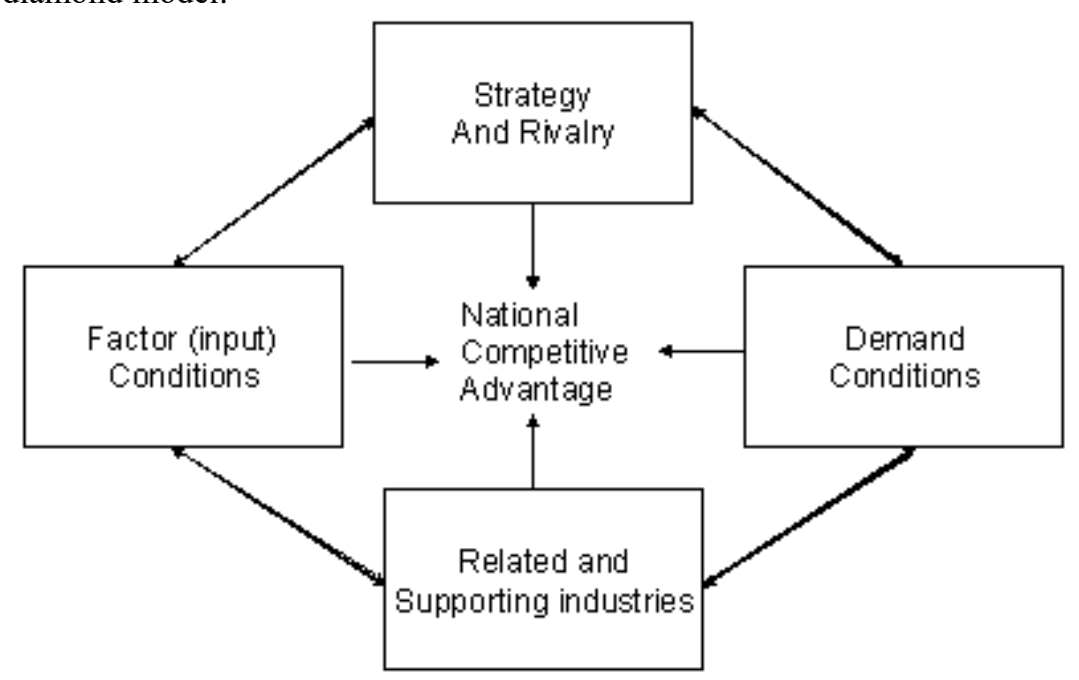

The regional factors which are set as criteria are presented in Figure 1, and are abbreviated to RF. In addition, RF3 and RF4 represent the available capital that falls under the Porter's factor conditions and reveal to a great extent the strategy which each regional government follows and the weight attributed to them. In order the comparisons in regional level to be conducted with actual measurements the absorbance of the EU Funds has been used. RF3 represents the funding availability for renewable energy firms through Structural Funds and the direct supporting of energy projects. The resource absorbance in entrepreneurship is a subsiding opportunity for investments that can be measured in regional level and embraces the different treatment in investments. EU funding for enterprises are very important for these kind of projects. RF4 represents the great extent to which investments and priorities contribute to upgrading energy infrastructure such as the energy grid. Regional energy infrastructure upgrading and modernisation through this priority of the Structural Funds are important for the future expansion of these kinds of investments. RF6, RF7 and RF2 represent the overall economic performance of each region. RF1 is related to the demand condition of the axis of Porter's diamond and RF10 to other installations and activities in a particular sector. The embracing of the RF10 embodies the agglomeration of the investments, revealing a positive or negative investment environmentMoreover, RF10 indicates the grid's quality as regions with high-concentration of investments means that these regions fulfil high quality infrastructures and enjoy high connectivity. RF5 is related to factor conditions as the land for solar parks needs non-urban non-arable ground in order for land acquisition to be economic for investment. We have chosen "land availability", instead of "price for the land" (representing a scarcity value of it) because it is comparable between the regions and the regional data is available and measurable by editing the data of Statistical Bureau. Furthermore, the approach of "Land availability" follows OECD. As underpinned by the OECD (2012, p.25) report "Due to the availability of both space and renewable sources of energy, rural regions attract a large share of this investment". High land availability can be expressed as high level of rurality and as a consequence more opportunities for investments. RF8 is related to the ability of finding specialised staff with skills in high-technology systems. Finally, RF9 is related to the existing environmental conditions and constitutes a significant factor condition as it defines the annual turnover.

The investment scenarios will be created through significance comparisons. At first, these are conducted to develop a scenario as a core; following this, by applying the sensitivity analysis of Expert Choice software, a table for the scenario is formed along with respective scores. 
With regards the first scenario, comparisons of the regions are initially conducted with respect to each criterion and with actual measurements from Eurostat-derived data during the period 2012-2014.In the next step, judgments of the criteria are made by using Saaty's rating scale (Saaty and Vargas, 2001). A basic scenario has been chosen in order to create low inconsistency. The consistency ratio of matrices comparing the alternatives with each criterion equals 0 , which means perfect consistency, because we compare each one with its actual measurements. In the matrix where the criteria are compared with one another, the consistency ratio is $0.01<0.1$, which means that the specific scenario is fully reliable for the basic scenario. It is important for the inconsistency to be at a low level as in the current case; indeed, this provides a high level of reliability for the scenario. The sensitivity analysis of Expert Choice was used to create different investment scenarios and their corresponding alternative scores. In this paper, and in order to enhance its practical usage, 10 scenarios have been created by granting, for each criterion, a weight of 20 per cent. The scenarios are presented in Table 2 . The range of scenarios gives to decision-makers, stakeholders and business managers a range of choices in order to take the most suitable decision.

Table 2. Ten investments scenarios.

\begin{tabular}{|c|c|c|c|c|c|c|c|c|c|c|c|c|c|}
\hline \multicolumn{14}{|c|}{ Crite } \\
\hline \multicolumn{2}{|c|}{ Scenario } & $R F 1$ & $R F 2$ & $R F 3$ & \multicolumn{2}{|c|}{ RF4 } & $R F 5$ & RF6 & RF7 & \multicolumn{2}{|c|}{$R F 8$} & $R F 9$ & RF 10 \\
\hline \multicolumn{2}{|c|}{ Basic } & 111.5 & 15.5 & 8.4 & \multicolumn{2}{|c|}{6.1} & 2.0 & 25.8 & 20.5 & \multicolumn{2}{|c|}{2.5} & 4.4 & 3,2 \\
\hline 1 & \multicolumn{2}{|r|}{11.4} & 9.5 & 9.0 & \multicolumn{2}{|c|}{9.3} & 9.1 & 20.0 & 7.4 & \multicolumn{2}{|c|}{7.0} & 8.4 & 8.9 \\
\hline 2 & \multicolumn{2}{|r|}{11.4} & 10.2 & 9.1 & \multicolumn{2}{|c|}{8.3} & 8.5 & 6.2 & 20.0 & \multicolumn{2}{|c|}{8.4} & 8.2 & 9.7 \\
\hline 3 & \multicolumn{2}{|r|}{11.0} & 20.0 & 12.2 & \multicolumn{2}{|c|}{11.1} & 6.7 & 8.3 & 8.5 & \multicolumn{2}{|c|}{7.7} & 8.1 & 6.3 \\
\hline 4 & \multicolumn{2}{|r|}{20.0} & 9.0 & 12.5 & \multicolumn{2}{|c|}{11.5} & 6.9 & 8.6 & 8.7 & \multicolumn{2}{|c|}{7.9} & 8.3 & 6.5 \\
\hline 5 & \multicolumn{2}{|r|}{8.2} & 6.9 & 20.0 & \multicolumn{2}{|c|}{14.9} & 9.8 & 8.7 & 8.6 & \multicolumn{2}{|c|}{6.4} & 8.4 & 8.0 \\
\hline 6 & \multicolumn{2}{|r|}{10.4} & 8.7 & 11.6 & \multicolumn{2}{|c|}{20.0} & 2.8 & 11.0 & 6.6 & \multicolumn{2}{|c|}{8.1} & 10.6 & 10.1 \\
\hline 7 & & 10.9 & 7.1 & 10.3 & & & 3.8 & 7.3 & 8.8 & & & 20.0 & 13.5 \\
\hline 8 & & 7.8 & 7.8 & 8.1 & & & 5.6 & 6.7 & 6.9 & & & 9.5 & 20.0 \\
\hline 9 & & 3.2 & 12.0 & 11.5 & & & 8.6 & 10.3 & 10.6 & & & 9.2 & 8.2 \\
\hline 10 & & 7.5 & 4.5 & 9.4 & & & 20.0 & 2.6 & 3.3 & & & 12.5 & 13.7 \\
\hline & & & & & & & ore \% & & & & & & \\
\hline Scen. & $R 1$ & $R 2$ & $R 3$ & $R 4$ & $R 5$ & $R 6$ & $R 7$ & $R 8$ & $R 9$ & $R 10$ & $R 11$ & $R 12$ & $R 13$ \\
\hline Basic & 6.2 & 8.9 & 6.5 & 6.8 & 6.1 & 6.9 & 9.3 & 7.2 & 15.0 & 5.6 & 8.3 & 7.2 & 6.2 \\
\hline 1 & 6.5 & 8.7 & 6.5 & 7.8 & 6.8 & 7.2 & 11.0 & 7.5 & 10.3 & 5.7 & 8.7 & 7.5 & 6.0 \\
\hline 2 & 6.7 & 8.7 & 6.6 & 7.7 & 7.0 & 7.3 & 9.8 & 7.6 & 10.3 & 6.0 & 8.7 & 7.6 & 6.2 \\
\hline 3 & 6.6 & 9.0 & 6.7 & 7.8 & 7.1 & 7.3 & 9.8 & 7.5 & 10.0 & 5.6 & 9.3 & 7.7 & 5.6 \\
\hline 4 & 7.0 & 9.0 & 6.4 & 7.7 & 6.8 & 7.8 & 10.3 & 7.9 & 9.9 & 5.8 & 8.3 & 7.0 & 6.1 \\
\hline 5 & 6.6 & 9.4 & 7.0 & 8.8 & 7.3 & 7.5 & 10.0 & 8.0 & 8.1 & 5.7 & 8.0 & 8.8 & 4.9 \\
\hline 6 & 6.5 & 8.8 & 6.9 & 7.8 & 6.7 & 7.2 & 10.0 & 7.7 & 10.3 & 5.8 & 8.5 & 7.8 & 5.9 \\
\hline 7 & 6.3 & 9.7 & 6.2 & 7.6 & 6.3 & 7.3 & 9.7 & 7.6 & 13.9 & 5.1 & 7.6 & 7.6 & 5.1 \\
\hline 8 & 6.5 & 9.3 & 6.8 & 7.8 & 7.1 & 7.4 & 8.5 & 7.4 & 11.9 & 5.8 & 8.3 & 7.8 & 5.6 \\
\hline 9 & 6.9 & 9.2 & 6.4 & 7.9 & 6.7 & 7.8 & 10.0 & 7.9 & 10.8 & 5.6 & 7.9 & 7.3 & 5.7 \\
\hline 10 & 7.0 & 9.8 & 6.2 & 8.4 & 6.7 & 8.2 & 10.1 & 8.3 & 10.3 & 5.3 & 7.2 & 7.2 & 5.2 \\
\hline
\end{tabular}

As demonstrated, the regional factors significantly affect regional competitiveness and their contribution is so strong that they do not significantly affect regions' ranking, despite the fact that we grant each criterion $20 \%$ importance. In all scenarios, R9, R7 and R2 are the regions with the highest performance following almost the same order. In scenarios 1, 4, 5 where the RF1, RF4 and RF5 are granted 20\% weight, region R7 ranks first instead of R9 which ranks first in all other scenarios. In scenario 8 where the RF8 criterion is granted $20 \%$ weight region 
R2 comes above R7. As can be inferred, there are no significant changes in the rank order despite the fact that $20 \%$ of additional weight is quite a high percentage, enough to alter the rank order. Regional factors are of decisive significance; therefore, their impact affects the place of investment in relation to other regions.

\section{Policy implications}

The expansion of renewable production and technologies through investment in solar parks and PV installations can promote sustainable development and encourage the creation of sustainable systems. This work can also contribute significantly to the expansion of renewable energy as is expressed through the United Nations Sustainable Development Goals (SDGs). By employing an AHP method to create investment scenarios for the renewable energy sector, we reach useful conclusions in terms of the scientific and practical dimensions of renewable energy. Despite the fact that intergovernmental agreements such as the last COP21 focus on the national level, in solar energy enterprises, where locality matters in new investments attraction, we must focus our analyses on the criteria affecting regional investment attractiveness and try to expound them from decision-making theory in order for them to have practical use in businesses.

\section{Conclusion}

What emerges from the above research and is directly linked with the novelty of this article is that investments scenarios must incorporate various regional parameters, thus multi-criteria methodology can prove extremely useful at the operational level.

Due to regional disparities, factors at the regional level play a crucial role in choosing the best region for investment in solar energy enterprises, and we can define the problem by employing a multi-criteria method. By developing ten scenarios and granting $20 \%$ priority to each criterion, we deduce that the ranking of the regions remains the same in almost all ten scenarios. This means that the regional factors perform a significant role in such a way that, despite the importance of the criteria, some regions remain highly competitive in comparison to others.

Our research draws attention to certain important future research avenues. First of all, the selection of the criteria can be expanded depending on the regional data availability. In case of different sub-national treatment in feed-in tariffs then regional feed-in tariff strategy should be embraced. The criteria selection of Punia Sindhu et al. (2016) in the case of regional data availability can be applied at the local level by following our approach. Land availability can be embodied as price per land indicating scarcity value. The regional approach put forth by Aragonés-Beltrán (2014) can be incorporated by conducting the comparisons with actual measurements, and by shrinking the effect of the human factor in Saaty's scale comparisons. Undoubtedly, a possible extension of this study is to apply the AHP method in the same way to regions in different countries while adopting a cross-national regional approach.

\section{References}

Afgan, N.H. and Carvalho, M.G. (2002) Multi-criteria assessment of new and renewable energy power plants, Energy, 27, 739-755.

Allan, G.P., McGregor, P. and Swales, K. (2011) The Importance of Revenue Sharing for the Local Economic Impacts of a Renewable Energy Project: A Social Accounting Matrix Approach, Regional Studies, 45(9), 1171-1186. 
Aragonés-Beltrán, P., Chaparro-González, F., Pastor-Ferrando, J-P., Pla-Rubio, A. (2014) An AHP (Analytic Hierarchy Process) / ANP (Analytic Network Process) - based multi-criteria decision approach for the selection of solar - thermal power plant investment projects, Energy 66:222-238.

Bull, S.R. and Billman, L. (1999) Renewable Energy: Ready to Meet Its Promise? The Washington Quarterly, 23(1), 229-244.

Chen, M.K. and Wang, S.C. (2010) The critical factors of success for information service industry in developing international market: Using analytic hierarchy process (AHP) approach, Expert Systems with Applications, 37, 694-704.

Commission of the European Community. (2008) Regions 2020: An assessment of future challenges for EU regions. http://ec.europa.eu/regional_policy/sources /docoffic/working/regions2020/pdf/regions2020_en.pdf (Accessed 2 January 2016).

Ernst and Young. (2012) Renewable energy country attractiveness indices. http://www.ey.com/Publication/vwLUAssets/Renewable_energy_country_attractiveness_indices_-_Issue_33/\$FILE/EY_RECAI_issue_33.pdf (Accessed 2 January 2016).

EurObserv'ER. (2015) Photovoltaic barometer. http://www.eurobserv-er.org/photovoltaic-barometer-2015/ (Accessed 2 January 2016).

European Commision. (2011) Energy Roadmap 2050. European Commission. http://ec.europa.eu/energy/energy2020/roadmap/doc/com_2011_8852_en.pdf (Accessed 2 January 2016).

European Union. (2011) Regional policy contributing to sustainable growth in Europe. European Union.

Feder, D. (2004) A Regionally Based Energy End-Use Strategy: Case Studies from Centre County Pennsylvania, The Professional Geographer, 56(2), 185-200.

Greek Ministry for Environment, Energy and Climate Change. (2010) National Renewable Energy Action Plan in the scope of Directive 2009/28/EC. Greek Ministry for Environment, Energy and Climate Change.

Hamalainen, R.P. and Karjalainen, R. (1992) Decision support for risk analysis in energy policy, European Journal of Operational Research, 56, 172-183.

He, Y. and Guo, S. (2011) Energy Strategy Develops Dominant Decision-Making Based on AHP. In: IEEE International Conference on Mechatronic Science, Electric Engineering and Computer, 19-22 August, Jilin.

International Energy Agency. (2015) Trends in 2014 in photovoltaic applications, Photovoltaic Power Systems Programme. Available at: http://iea-pvps.org/fileadmin/dam/public/report/statistics/IEA_PVPS_Trends_2014_in_PV_Applications_-_lr.pdf (Accessed 25 January 2016).

Jovanović, B., Filipović, J., Vukman, B. (2015) Prioritization of manufacturing sectors in Serbia for energy management improvement - AHP method, Energy Conversion and Management 98(1):225-235.

Ke, C., Dang, F. and Wang, J. (2011) Application of AHP in the selection of our country wind farm's location. International Conference on Management and Service Science. 12-14 Aug, Wuhan.

Kearns, G.S. (2004) A multi-objective, multi-criteria approach for evaluating IT investments: Results from two case studies. Information Resources Management Journal, 17(1), 3762.

Lee, S.K., Mogi, G. and Kim, J.W. (2008) The competitiveness of Korea as a developer of hydrogen energy technology: The AHP approach, Energy Policy, 36, 1284-1291.

Motohashi, K. (1998) Innovation strategy and business performance of Japanese manufacturing firms, Economics of Innovation \& New Technology, 7(1), 27-52. 
Prahalad, C.K. and Hamel, G. (1990) The core competence of the corporation. Harvard Business Review, 68(3), 79-93.

Punia Sindhu, S., Nehra, V., Luthra, S. (2016) Recognition and prioritization of challenges in growth of solar energy using analytical hierarchy process: Indian Outlook, Energy 100(1):332-348.

Nagesha, N. and Balashandra, P. (2006) Barriers to energy efficiency in small industry clusters: Multi-criteria-based prioritization using the analytic hierarchy process, Energy, 31(12), 1969-1983.

Nevima, J. and Kiszova, Z. (2012) Evaluation of regional competitiveness - case study of Visegrad - Four regions using an analytic hierarchy process. In: 3rd International conference on development, environment, energy, economics, 2-4 December. Paris.

Organisation for Economic Co-operation and Development. (OECD). 2012 Inclusive Green Growth: For the future we want. OECD.

Porter, M.E. (1990) The Competitive Advantage of Nations, MacMillan Press Ltd.

Saaty, T.L, Vargas, L.G. and Dellmann, K. (2003) The allocation of intangible resources: The analytic hierarchy process and linear programming. Socio-Economic Planning Science, 37(3), 169-184.

Saaty, T.L. and Vargas, L.G. (2001) Models, methods, concepts and applications of the analytic hierarchy process. New York: Springer Science and Business Media.

Secme, N.Y., Bayrakdaroglu, A. and Kahraman, C. (2009) Fuzzy performance evaluation in the Turkish Banking Sector using Analytic Hierarchy Process and TOPSIS. Expert Systems with Applications, 36, 11699-11709.

Solar Power Europe. (2015) Global Market Outlook for Solar Power 2015-2019. Available at: http://www.solarpowereurope.org/ (Accessed 20 December 2015).

Toossi. A., Camci, F. and Varga, L. (2013) Developing an AHP based decision model for energy systems policy making. In: IEEE International Conference on Industrial Technology (ICIT), 25-28 Feb, Cape Town.

Wang, G., Huang, S.H. and Dismukes, J.P. (2004) Product-driven supply chain selection using integrated multi-criteria decision making methodology, International Journal of Production Economics 91(1), 1-15.

Wang, X. and Feng, Z. (2002) Sustainable development of rural energy and its appraising system in China. Renewable and Sustainable Energy Reviews, 6(4), 395-404.

Wu, J. and Wu, N. (1984) Analyzing Multi-dimensional Attributes for the Single Plant Location Problem via an Adaptation of The Analytic Hierarchy Process. International Journal of Operations \& Production Management, 4(3), 13-21.

Xiao, J. (2012) Evaluation of Sustainable Competitiveness of the Textile Industry Based on AHP. In: IEEE International Conference on Management of e-Commerce and e-Government. 20-21 October, Beijing. 